\title{
Effect of exogenous changes in heart rate upon mental performance in patients treated with artificial pacemakers for complete heart block ${ }^{1}$
}

\author{
Krister Lagergren \\ From the Department of Psychiatry, Karolinska sjukhuset, Stockholm, Sweden
}

The performance of 12 patients treated with artificial pacemakers for complete heart block was measured with psychological tests at heart rates of about 72 and 47 beats a minute. Performance was consistently better at the higher rate, and the difference was statistically significant in 10 out of the 16 measurements employed. The changes in performance in association with the alterations in heart rate might be explained in terms of differences in circulatory dynamics between the two heart rates with consequent cerebral hypoxia at the lower rate, or of variations in the psychophysiological condition based on the hypothesis of a cardiac-central nervous system feedback mechanism.

Patients suffering from a slow heart rate caused by acquired complete heart block often show cerebral symptoms, such as syncopal convulsive episodes, dizziness, or clouding of the sensorium (Penton, Miller, and Levine, 1956; Johansson, 1966). Treatment of these patients with artificial pacemakers has proved successful not only in restoring their heart rates, but also in relieving their cerebral symptoms (Landegren and Biörck, 1963; Harris et al., 1965; Edhag, 1969). It has been observed that the treatment also improved memory and mental acuity in many such patients (Schwedel and Escher, I964; Zoll, Frank, and Linenthal, 1964; Dalessio, Benchimol, and Dimond, 1965; Becker et al., 1967; Greene and Moss, 1969).

The purpose of the present investigation was to study if changes in heart rate have an effect upon mental performance of patients treated with artificial pacemakers for complete heart block.

\section{Subjects}

Twelve patients, 4 men and 8 women, treated with permanent artificial pacemakers because of acquired complete heart block were chosen for the study. They were between 50 and 82 years of age, with a median age of 67.5 years. None of them suffered from other diseases.

Received 24 April 1974.

${ }^{1}$ This work was supported by grants from the Swedish National Association against Heart and Chest Diseases and from the Swedish Society of Medical Sciences.
They had all been operated upon as described by Lagergren and Johansson (1963) and carried the impulse generators (Elema-Schönander, EM 138 or EM 145) externally. The duration of treatment before the investigation ranged from 7 to 408 days, with a median of 37 days. Before treatment, 8 of the patients suffered from syncopal attacks, 3 from dizziness, and I from general fatigue at idioventricular rates ranging from 15 to 40 beats a minute, with a mean of 34 beats. All these symptoms had been promptly relieved by the treatment.

The patients, who were fully informed about the investigation, apart from the heart rates to be used, gave their informed consent and voluntarily participated.

\section{General design}

A single-blind investigation was performed according to a repeated measures design, in which each patient was studied at both a 'normal' and a slow heart rate, the order of which was varied in that half of the patients started the study at the slow and the other half at the 'normal' rate.

At the 'normal' frequency, the pacemaker was adjusted to give a stable heart rate of about 70 beats a minute. At the slow frequency, it was adapted to give the slowest possible rate without interference from the patient's own idioventricular rhythm. The changes in frequency were concealed from the patient.

At each heart rate, the patient underwent a fixed testing programme, which included the Benton test, the critical fusion frequency test, the digit symbol test, handwriting, the KS memory test-battery, the Krakau visual acuity test, the choice reaction time test, the reversed choice reaction time test and self-ratings. 


\begin{abstract}
Methods
Psychometric variables

Benton visual retention test This consists of ro cards with drawings of simple geometric figures, each of which is to be reproduced from memory after an inspection period of ro seconds. It is designed for testing visual memory, visual perception, and visuomotor skill. There are three parallel versions of the test cards. The test was scored in two ways according to the manual (Benton, 1963): the number of correct figures and the total number of various kinds of errors on all drawings.
\end{abstract}

Digit symbol test This is a code learning test, similar to that included in the WAIS (Wechsler, 1958), in which digits from $I$ to 9 are paired with simple symbols. The patient has to write as many correct symbols as possible within a time limit of 90 seconds under a series of digits printed on a sheet of paper. The test is designed for evaluating visuomotor skill. Three parallel versions of the test were used.

Handwriting The patients were asked to write a sample of 5 words by hand. The words were chosen for a suitable proportion of letters with a small height, like ' $a$ ' or ' $m$ ', and letters with an upward extension, like ' $h$ ' or ' $l$ '. The same sample or words was used in both sessions. The following measures were recorded: average small letter height, average extension height, and the total base length of the words written (Legge, Steinberg, and Summerfield, 1964).

KS memory test-battery (Cronholm, 1969). This consists of 3 subtests, 2 of which were used in this study. In the 30-figure test, the patient is shown a picture with 30 common objects which are pointed out and named. On a new picture, where the 30 objects are mixed with others, the patient is asked to indicate those which he recognizes. The 30-word-pair test is a paired associates test. The task is to learn 3 series with ro word pairs in each, which are read and shown to the patient. At recall testing the first word in each pair is given in a different order and the patient is requested to give the second. Recall was tested immediately and after 90 minutes, thus giving one 'immediate memory score' and one 'delayed memory score' in each subtest. There are two parallel versions of the test. The result was scored according to the number of correct recollections.

\section{Perceptual and psychomotor variables}

Critical fusion frequency test (CFF) the discrimination of intermittent light was measured with a device described by Milfeldt (1957) and Ideström (1962). A dim glowing lamp is fixed to the point of a conical funnel and the opening of the funnel is shaped to fit the face of the patient. The intermittent light is produced by means of a square wave generator. After 20 minutes of dark adaptation, the measurements were made in a constant faint light. The frequency of flashes was increased or decreased by turning a knob until fusion of flicker was perceived by the patient. Ten measurements were made: 5 with increase and 5 with decrease of the frequency, starting from different positions. The result was scored as the mean frequency of flashes at threshold (critical fusion).

Krakau visual acuity test (KVAT) Vernier visual acuity was measured with an automatic device described by Krakau (1967). The stimulus is a period of a squarewave displayed on an oscilloscope screen. The squarewave has either a positive (upward) or negative (downward) deflection ( $\longrightarrow$ ). The patient, who is seated at a distance of 4 metres from the oscilloscope, responds by pressing one of two buttons, 'up' or 'down'. The test consists of a series of stimulus presentations. The stimuli are presented in random order as regards the sign of the square-wave deflection. The amplitude of the deflection varies within a range of 25 fixed levels according to the following principle. Three successive correct responses cause the amplitude to decrease by one step, while one incorrect response increases it by one step. The stimulus presentation time, equal to maximum reaction time allowed, was $2.5 \mathrm{sec}$. The interstimulus interval was $0.5 \mathrm{sec}$. The amplitude of the deflection was continuously recorded on an inkwriter. The duration of the test was 7 minutes, of which the first two and last two were disregarded. Performance was scored as the arithmetical mean of the amplitudes recorded during the remaining 3 minutes. Numerically higher values correspond to smaller deflections of amplitude and thus to better performance.

Choice reaction time test (CRT) In response to two visual stimuli, choice reaction time was measured with a device adapted from King (1954) and described by Ideström (1962). It consists of a keyboard on which three circular steel electrodes are placed, corresponding to the corners of an isosceles triangle, with its apex directed towards the patient and its base towards a vertical panel with two horizontally placed stimuli lamps, one situated above each base electrode. The electrode at the apex is the resting electrode and the two base electrodes are the right and the left target electrodes. The patient waits for the stimulus with his hand of choice on the resting electrode. Right or left stimuli are presented in random order by an automatic device. The rest period depends upon the immediately preceding reaction time and varies between 3 and ro seconds. An electrical current of $\mathrm{a}$ few $\mu \mathrm{A}$ is passed through the patient and parts of the device via an indifferent electrode. Changes in the current trigger a counter used for recording the time interval from the moment the stimulus lamp is lit until the patient has moved his hand from the resting electrode to the target electrode over which the stimulus lamp is lit. After a training series of ro stimuli, 3 series of 20 stimuli were presented. There was an interval of about 20 minutes between the series. The result was scored as the mean of each series in hundreds of seconds.

Reversed choice reaction time test (rev. CRT) This is the same as the choice reaction time test, except that the target electrode is the one over which the stimulus lamp is not lit. Only one series of 20 stimuli, pre- 
ceded by a training series of 20 stimuli, was presented. The result was scored as the mean of the 20 stimuli.

\section{Subjective variables}

Self-ratings: a graphic rating scale was used (Guilford, 1954). A sheet of paper with horizontal lines representing the variables to be rated was shown to the patient. The lines were $17 \cdot 2 \mathrm{~cm}$ long. The patient's habitual states in the variables were defined by the centres of the lines and his extreme negative and positive states in the variables were specified alternatively by the left or right ends of the lines. For each variable, the patient was asked to mark a point on the line corresponding to his actual state in the variable as compared to his habitual state in the same variable. The variables rated were degree of concentration, sleepiness, efficiency, alertness, depression, and discomfort. They were scored according to their distance from the centres. A positive value indicated that the patient felt better than usual in the variable and a negative value implied that he felt worse.

\section{Procedure}

Each patient was studied on 3 consecutive days during which he was in hospital.

On the first day he was given a training session with the following tests: the Krakau visual acuity test (KVAT), the critical fusion frequency test (CFF), the choice reaction time test (CRT), the reversed choice reaction time test (Rev. CRT), self-ratings, and the digit symbol test. He was also given a thorough medical and neurological examination.

The second and third days were scheduled for the testing sessions which were performed in the afternoons.

Ten minutes before each session, the pacemaker was adjusted to give the desired impulse frequency, which was then kept constant throughout the session. The adjustment, which was made by turning a knob on the impulse generator, was concealed from the patient, who was also uninformed about the heart rate to be used.

Each session was divided into two periods of 60 and 30 minutes with a resting period of 20 minutes. The resting period was also used for adaptation to darkness before the CFF test.

The sequence of tests was: the KS memory test (immediate recall), self-ratings I, CRT $(10+20)$, the Benton test, the digit symbol test, handwriting, CRT II (20), CFF, CRT III (20), Rev. CRT $(20+20)$, KVAT, the KS memory test (delayed recall), and self-ratings II.

When possible, parallel versions of the tests were used in order to neutralize the effects of previous sessions.

The tests were given by a fully trained psychologist and were performed with the patient seated in a comfortable wheelchair which was moved between the different stations in the laboratory.

The patient was asked after each session if he had noticed any change in his heart rate.

During the sessions, a small photoplethysmographic pulse transducer (Grass) was attached to the patient's right ear-lobe and the pulse curve was continuously recorded on a mingograph ink-writer (Elema-Schön- ander). With the aid of a praecordial lead, electrocardiograms were also recorded on the mingograph.

\section{Results}

The complete testing programme was carried out without complications.

The results were calculated as total mean values and standard deviations.

At the 'normal' pacemaker frequency, the mean of the heart rates was $72 \cdot 3$ beats a minute ( $\mathrm{SD}=$ $3.0)$ and at the slow frequency it was 46.8 beats a minute $(S D=4 \cdot 6)$.

None of the patients knew at what heart rate he/ she was being studied and, on direct question, ro of the patients had not noticed any change whatsoever in their heart rates. One patient thought he noticed a slight decrease of about ro beats a minute at the slow heart rate and another thought it was a little slower than usual when 'normal'.

The results obtained in the pscyhometric variables are shown in Table $I$ and in the perceptual and psychomotor variables in Table 2.

The performance displayed a consistent tendency to be better at the 'normal' heart rate than at the slow rate. In spite of a large interindividual variability, the differences as estimated by t-tests were statistically significant in Io out of the 16 measures employed (see Tables).

In the Benton test, the patients reproduced fewer correct figures and made significantly more errors at the slow than at the 'normal' heart rate, and in the digit symbol test they wrote significantly fewer symbols at the slow heart rate. Handwriting tended to increase in size at the slow heart rate and this was significant for the average extension height of letters like ' $h$ ' and ' $l$ '. In the $30-$ figure test, the memory scores were inclined to decrease at the slow heart rate, and in the 30-wordpair test this decrease was significant for both immediate and delayed memory scores. The fusion threshold in the critical fusion frequency test was significantly higher at the 'normal' heart rate, as was the performance level in the Krakau visual acuity test. Finally, the reaction time was significantly shorter in 2 of the 3 choice reaction time tests and in the reversed choice reaction time test at the 'normal' heart rate.

In order to examine further the results obtained in the choice reaction time tests, a three-way analysis of variance, mixed model (Winer, r962), was employed (Table 3). This analysis showed that two variance sources contributed significantly to the total variance. First, there was a highly significant main effect 'normal' vs slow heart rate, the reaction time being longer at the slow rate. Secondly, there was a significant interaction patients 
TABLE I Mean values and standard deviations of results in psychometric variables at 'normal' and slow heart rates, $t$-tests for differences and product-moment coefficients of correlation $(r)$ between two conditions $(N=I 2)$

\begin{tabular}{|c|c|c|c|c|c|c|}
\hline & \multicolumn{2}{|c|}{ 'Normal' heart rate } & $\begin{array}{l}\text { Slow } h \\
\text { Mean }\end{array}$ & SD & t-value & $r$ 'Normal'-slow \\
\hline \multicolumn{7}{|l|}{ Benton } \\
\hline No. correct & $5 \cdot 9$ & $2 \cdot 4$ & $4 \cdot 8$ & $2 \cdot 0$ & $2 \cdot 17^{\star}$ & 0.68 \\
\hline No. of errors & $6 \cdot 1$ & $4 \cdot 5$ & $8 \cdot 5$ & $3 \cdot 9$ & $-3 \cdot 62 \ddagger$ & 0.85 \\
\hline Digit symbols & $32 \cdot 0$ & $7 \cdot 2$ & $30 \cdot 0$ & $8 \cdot 0$ & $2 \cdot 26 t$ & 0.88 \\
\hline \multicolumn{7}{|l|}{ Handwriting } \\
\hline Total base length & $158 \cdot 2$ & $27 \cdot 3$ & $165 \cdot 7$ & $22 \cdot 6$ & $-1 \cdot 73^{\mathrm{NS}}$ & 0.82 \\
\hline Extension height & 6.6 & $2 \cdot I$ & $7 \cdot 1$ & $2 \cdot 0$ & $-2.8 \mathrm{It}$ & 0.96 \\
\hline Small letter height & 3.4 & 0.8 & 3.5 & 0.7 & $-I \cdot 6 I^{N S}$ & 0.95 \\
\hline \multicolumn{7}{|l|}{$\begin{array}{l}K S \text { memory test } \\
\text { 30-figure test }\end{array}$} \\
\hline Immediate memory score & $26 \cdot 3$ & $3 \cdot 7$ & $24 \cdot 8$ & $4 \cdot 6$ & $\mathrm{r} \cdot 65^{\mathrm{NS}}$ & 0.71 \\
\hline delayed memory score & $24 \cdot 4$ & $4 \cdot 1$ & $24 \cdot 3$ & $4 \cdot 2$ & $0.07^{\mathrm{NS}}$ & 0.50 \\
\hline \multicolumn{7}{|l|}{ 30-word-pair test } \\
\hline Immediate memory score & $24 \cdot 7$ & $3 \cdot 0$ & $21 \cdot 8$ & $4 \cdot 8$ & $2.53 \dagger$ & 0.52 \\
\hline Delayed memory score & 20.8 & $2 \cdot 6$ & 16.9 & $4 \cdot 3$ & $3.23 \dagger$ & 0.31 \\
\hline
\end{tabular}

NS = non-significant, ${ }^{\star}=P<0.1, \dagger=P<0.05, \ddagger=P<0.01$.

vs heart rate indicating that there was a variation in degree of improvement in reaction time of the different patients in the transfer from slow to 'normal' heart rate but, that this variation was far too small to account for the main effect of heart rate. Furthermore, from the analysis it was inferred that there was no difference in mean values between the three CRT measurements, and no interaction patients vs CRT measurements; thus, there was a high correlation between the results in CRT I, II, and III for the patients. Finally the decrement in performance associated with the slow heart rate was manifest to the same degree in all three CRT measurements.
Self-ratings were made in the beginning and at the end of each testing session. The results are shown in Table 4. On statistical examination, the first and the second ratings did not differ significantly and there was no significant difference between the 'normal' and the slow heart rates in any of the variables rated. This lack of difference may partly be caused by the large interindividual variability within each rating, which is indicated by the low coefficients of correlation between 'normal' and slow heart rates.

The medical and neurological examination of the patients did not reveal any abnormal conditions apart from the complete heart block.

TABLE 2 Mean values and standard deviations of results in perceptual and psychomotor variables at 'normal' and slow heart rates, $t$-tests for differences and product-moment coefficients of correlation ( $r$ ) between two conditions $(N=12)$

\begin{tabular}{|c|c|c|c|c|c|c|}
\hline & \multicolumn{2}{|c|}{ 'Normal' heart rate } & \multicolumn{2}{|c|}{ Slow heart rate } & t-value & $r$ 'Normal'-slow \\
\hline CFF & $35 \cdot 0$ & $2 \cdot 2$ & $34 \cdot 1$ & $I \cdot 7$ & $2 \cdot 79 t$ & 0.88 \\
\hline $\begin{array}{l}\text { KVAT } \\
\text { CRT }\end{array}$ & $16 \cdot 1$ & $4 \cdot 3$ & 15.4 & $4 \cdot 1$ & $2 \cdot 28 t$ & 0.96 \\
\hline $\begin{array}{c}\text { I } \\
\text { II } \\
\text { III } \\
\text { Rev CRT }\end{array}$ & $\begin{array}{l}62 \cdot 4 \\
6 I \cdot 3 \\
6 I \cdot I \\
82 \cdot 4\end{array}$ & $\begin{array}{r}10 \cdot 9 \\
8.4 \\
9.8 \\
22 \cdot 9\end{array}$ & $\begin{array}{l}65 \cdot 8 \\
66 \cdot 4 \\
67 \cdot 6 \\
92 \cdot 2\end{array}$ & $\begin{array}{l}\text { II } 1 \\
10 \cdot 6 \\
11 \cdot 7 \\
25 \cdot 3\end{array}$ & $\begin{array}{l}-1 \cdot 36^{\mathrm{Ns}} \\
-3 \cdot 17 \ddagger \\
-3.67 \ddagger \\
-3 \cdot 14 \ddagger\end{array}$ & $\begin{array}{l}0.68 \\
0.84 \\
0.84 \\
0.90\end{array}$ \\
\hline
\end{tabular}

NS = not significant, $\dagger=P<0.05, \ddagger=P<0.01$. 
TABLE 3 Three-way analysis of variance table for $I 2$ patients, three choice reaction time tasks at 'normal' and slow heart rates

\begin{tabular}{lrrl}
\hline Source of variance & Mean square & d.f. & F-ratio \\
\hline A Patients & $5,278,210$ & II & \multicolumn{1}{c}{-} \\
B 'Normal'-slow & $4,026,370$ & I & $53 \cdot 60 \Omega$ \\
C) CRT I, II, III & 27,904 & 2 & $0 \cdot 37^{\mathrm{NS}}$ \\
A $\times$ B & 526,476 & II & $7 \cdot 01 \ddagger$ \\
A C & 45,441 & 22 & $0 \cdot 61^{\mathrm{NS}}$ \\
B $\times$ C & 218,624 & 2 & $2 \cdot 91^{\mathrm{NS}}$ \\
Error & 75,124 & 22 & -
\end{tabular}

NS = non-significant, $\ddagger=P<0.01, \oint=P<0.001$.

\section{Discussion}

The main finding in this study was that the mental performance of patients treated with artificial pacemakers for acquired complete heart block was better, as measured with a battery of perceptual, psychomotor, and psychometric tests, at a heart rate of about 72 than at one of about 47 beats a minute.

Although it has been observed that the treatment with artificial pacing often improves memory and mental acuity in such patients (Schwedel and Escher, 1964; Zoll et al., 1964; Dalessio et al., 1965; Becker et al., 1967; Greene and Moss, 1969), it has not been experimentally demonstrated before.

It is a matter for discussion whether the difference in performance does not merely reflect psychological effects or expectations of the patients in regard to the alterations of their heart rates.
In the present study, the patients did not know at what heart rates they were being investigated and the changes in the impulse frequency of their pacemakers were made in such way that they were unaware of the change. That the patients did not feel the change may also be due to the circumstance that the imposed decrease in heart rate was less pronounced than the ones they had previously experienced at their idioventricular rates. Furthermore, the self-ratings showed that the patients felt the same as usual during the sessions and that they did not feel any difference between the 'normal' and the slow heart rates. Thus, in all probability, their performance was not influenced to any major degree by psychological effects or expectations.

The occurrence of syncopal attacks and reversible cerebral symptoms in patients with complete heart block strongly suggests associated underlying, inadequate cerebral perfusion.

In the present study, performance was measured with tests considered to be sensitive indicators of the alterations in the psychophysiological condition caused by hypoxia. The 'impairment' of the performance displayed at the slow heart rate in this study was also similar to that generally found in connexion with hypoxia (Van Liere and Stickney, 1963). However, since the psychological tests do not exclusively measure such alterations, any hypothesis that the impairment was caused by hypoxia must be based on circumstantial evidence.

Patients with slow heart rates caused by acquired complete heart block usually have low cardiac output, low mean arterial blood pressure, and wide arteriovenous oxygen difference (Levinson et al.,

TABLE 4 Mean values and standard deviations of results in subjective variables at 'normal' and slow heart rates, $t$-tests for differences and product-moment coefficients of correlation $(r)$ between two conditions

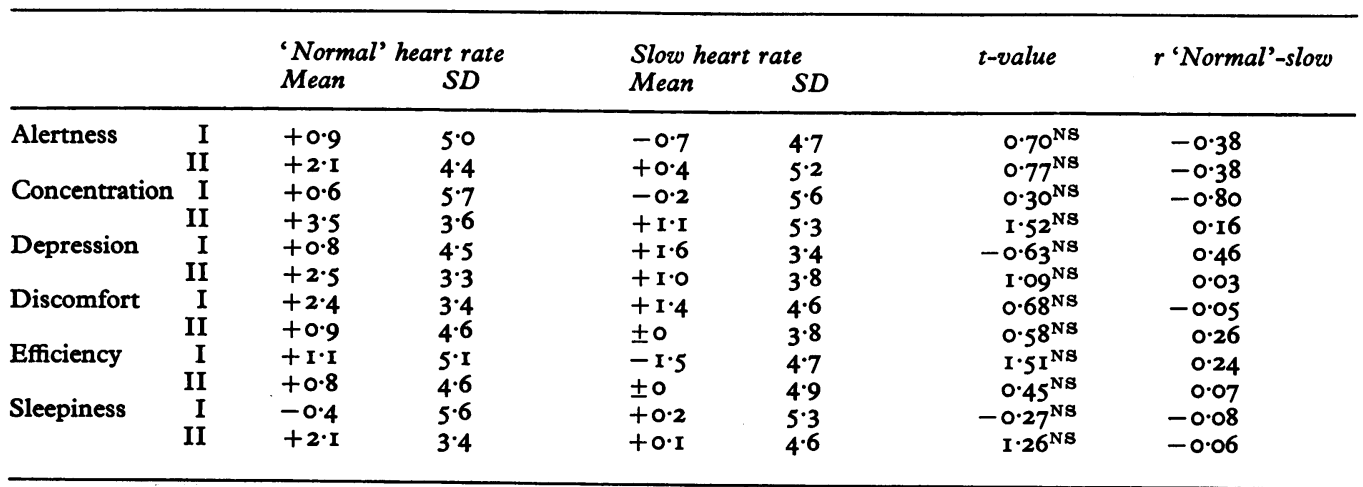

NS = non-significant. 
1959). The incidence of syncopal attacks in such patients is approximately 60 per cent (Penton et al., 1956), a figure that corresponds to that found before treatment in the present cases.

Management of acquired complete heart block with artificial pacing usually increases cardiac output (Escher et al., 1964; Samet et al., 1964; Segel et al., 1964; Bevegård et al., 1967). Accordingly, it has been suggested that artificial pacing, by increasing the output, also increases the cerebral circulation (Dalessio et al., 1965). This assumption was supported by Shapiro and Chawla (1969), who by using the nitrous oxide method demonstrated that artificial pacing increases both cardiac output and cerebral blood flow in patients with complete heart block. That artificial pacing may increase cerebral blood flow in such patients has also been shown with the ${ }^{133}$ Xenon clearance method by Sulg et al. (1969), and with serial angiographies by Lagergren et al. (1973).

Shapiro and Chawla (1969) and Sulg et al. (1969) discussed their findings in reference to the concept of the autoregulatory capacity of the cerebral vasculature and concluded that in this context the autoregulation seemed to be disturbed.

Apart from the increase in the systemic circulation, artificial pacing is usually also associated with an increase in mean arterial blood pressure and a narrowing of arteriovenous oxygen difference, changes which are all reversed if the heart rate is again reduced (Escher et al., 1964; Samet et al., 1964; Segel et al., 1964; Bevegård et al., 1967; Shapiro and Chawla, 1969).

The prompt disappearance of cerebral symptoms in the present group of patients after the treatment with artificial pacing was started may indicate an increase in the cerebral circulation. The subsequent slow down of the impulse frequency may then again have caused a temporary reduction in the cerebral circulation of the patients.

Thus, if there was a reduction in the systemic circulation when the heart rate was lowered from about 72 to about 47 beats a minute, it seems possible that the 'impairment' of the performance at the slow heart rate was caused by a cerebral hypoxia related to a disturbance in the cerebral circulation. Inversely, the 'improvement' of the performance at the 'normal' heart rate may be explained as the effect of a normalization of the cerebral circulation.

However, there has also been speculation as to whether the heart rate per se may have some effect on the psychophysiological condition. Lacey, for instance, has proposed an activation theory in which one of the key concepts is 'visceral afferent feedback from the cardiovascular system to the brain, which has inhibitory rather than excitatory effects' (Lacey, 1967). According to such hypotheses another explanation of the present findings would perhaps be that the alterations in heart rate per se might have had an effect on the performance of the patients, presumably in the form of changes in vigilance or cortical arousal. The fact that the circulatory dynamics are different in the sitting from those in the supine position might be relevant in this context and presumably even more so in patients with complete heart block, artificially paced at a low frequency.

A study similar to the present one is in progress, with the patients in both supine and sitting positions.

The author is grateful to Dr. Daisy Schalling for constructive suggestions regarding the test programme, to Dr. Sten Levander for his aid with the statistical analyses, and to Mr. Jan-Erik Olsson for his help with the psychological tests.

\section{References}

Becker, M. C., Zucker, I. R., Parsonnet, V., and Gilbert, L. (1967). Rehabilitation of the patient with a permanent pacemaker. Geriatrics, 22, 106.

Benton, A.-L. (1963). The Revised Visual Retention Test; Clinical and Experimental Applications. The Psychological Corporation, New York.

Bevegård, S., Jonsson, B., Karlöf, I., Lagergren, H., and Sowton, E. (1967). Effect of changes in ventricular rate on cardiac output and central pressures at rest and during exercise in patients with artificial pacemakers. Cardiovascular Research, $\mathbf{1}, 2 \mathrm{I}$.

Cronholm, B. (1969). Post-ECT amnesia. In The Pathology of Memory, pp. 81-89. Ed. by G. A. Talland and N. C. Waugh. Academic Press, New York.

Dalessio, D. J., Benchimol, A., and Dimond, E. G. (1965) Chronic encephalopathy related to heart block; its correction by permanent cardiac pacemaker. Neurology, $15,499$.

Edhag, O. (1969). Long-term cardiac pacing: experience of fixed-rate pacing with an endocardial electrode in 260 patients. Acta Medica Scandinavica, 186, Suppl. 502.

Escher, D. J. W., Schwedel, J. B., Schwartz, L. S., and Solomon, N. (1964). Transvenous-electrical stimulation of the heart. Annals of the New York Academy of Sciences, III, 981 .

Greene, W. A., and Moss, A. J. (1969). Psychosocial factors in the adjustment of patients with permanently implanted cardiac pacemakers. Annals of Internal Medicine, 70, 897.

Guilford, J. P. (1954). Psychometric Methods, 2nd ed., pp. 265269. McGraw-Hill, New York.

Harris, A., Bluestone, R., Busby, E., Davies, G., Leatham, A., Siddons, H., and Sowton, E. (1965). The management of heart block. British Heart fournal, 27, 469.

Ideström, C.-M. (1962). The effect of $\gamma$-phenyl-propylcarbamate compared with meprobamate and placebo; an experimental psychological study. Psychopharmacologia, 3, 15.

Johansson, B. W. (1966). Complete heart block. A clinical, hemodynamic and pharmacological study in patients with and without an artificial pacemaker. Acta Medica Scandinavica, 180, Suppl. 451 .

King, H. E. (1954). Psychomotor Aspects of Mental Disease, Ist ed., p. 178. Harvard University Press, Cambridge, Massachusetts.

Krakau, C. E. T. (1967). An automatic apparatus for time series analysis of visual acuity. Vision Research, 7, 99. 
Lacey, J. (1967). Somatic response patterning and stress: some revisions of activation theory. In Psychological Stress, pp. 14-39. Ed. by M. H. Appley and R. Trumbull. Appleton-Century-Crofts, New York.

Lagergren, H., and Johansson, L. (1963). Intracardiac stimulation for complete heart block. Acta Chirurgica Scandinavica, 125, 562 .

Lagergren, K., Marions, O., Swensson, A., and Karlöf, I. (1973). Effects of cardiac pacing on the cerebral circulation: an angiographic study. Investigative Radiology, 8, III.

Landegren, J., and Biörck, G. (1963). The clinical assessment and treatment of complete heart block and Adams-Stokes attacks. Medicine, 42, I7I.

Legge, D., Steinberg, H., and Summerfield, A. (1964). Simple measures of handwriting as indices of drug effects. Perceptual and Motor Skills, 18, 549.

Levinson, D. C., Shubin, H., Gunther, L., and Meehan, J. P. (1959). Hemodynamic findings in heart block with slow ventricular rates. American fournal of Cardiology, 4, 440.

Milfeldt, M. (1957). Flimerfusion og vibrationssans $i$ neurologine. (Flicker-Fusion in Neurology.) Universitetsförlaget, Århus.

Penton, G., Miller, H., and Levine, S. (1956). Some clinical features of complete heart block. Circulation, 13, 801 .

Samet, P., Bernstein, W. H., Medow, A., and Nathan, D. A. (I964). Effect of alterations in ventricular rate on cardiac output in complete heart block. American fournal of Cardiology, 14, 477 .
Schwedel, J. B., and Escher, D. J. W. (1964). Transvenous electrical stimulation of the heart. Annals of the New York Academy of Sciences, III, 972.

Segel, N., Hudson, W. A., Harris, P., and Bishop, J. M. (I964). The circulatory effects of electrically induced changes in ventricular rate at rest and during exercise in complete heart block. Fournal of Clinical Investigation, 43, I54I.

Shapiro, W., and Chawla, N. P. S. (1969). Observations on regulation of cerebral blood flow in complete heart block. Circulation, 40, 863.

Sulg, I. A., Cronqvist, S., Schüller, H., and Ingvar, D. H. (1969). The effect of intracardial pacemaker therapy on cerebral blood flow and EEG in patients with complete atrioventricular block. Circulation, 39, 487.

Van Liere, E. J., and Stickney, J. C. (1963). Hypoxia, pp. 276349. University of Chicago Press, Chicago.

Wechsler, D. (1958). The Measurement and Appraisal of Adult Intelligence, 4 th ed. Williams and Wilkins, Baltimore.

Winer, B. J. (1962). Statistical Principles in Experimental Design, Ist ed., pp. 248-257. McGraw-Hill, New York.

Zoll, P. M., Frank, H. A., and Linenthal, A. J. (1964). Fouryear experience with an implanted cardiac pacemaker. Annals of Surgery, 160, 35I.

Requests for reprints to Dr. Krister Lagergren, Psychiatric Department, Karolinska sjukhuset, IO4 OI Stockholm 60, Sweden. 